\title{
Effect of Tribological Properties on Boron Carbide and CNT Reinforced Copper based Composites
}

\author{
Dr. Tukaram Jadhav ${ }^{* 1}$, Dr. H. K. Shivanand ${ }^{2}$, Dr. Ranjith V', Verma R ${ }^{4}$, Puneeth $\mathrm{P}^{5}$ \\ ${ }^{* 1}$ Guest Faculty, Mechanical Engineering, Bangalore University, UVCE, Bangalore, Karnataka, India \\ ${ }^{2}$ Professor, Mechanical Engineering, Bangalore University, UVCE, Bangalore, Karnataka, India \\ ${ }^{3}$ Assistant Professor, Mechanical Engineering, Dr. AIT, Bangalore, Karnataka, India \\ ${ }^{4}$ Ph.D Scholar, Mechanical Engineering, Bangalore University, UVCE, Bangalore, Karnataka, India \\ ${ }^{5}$ PG Scholar, Mechanical Engineering, Bangalore University, UVCE, Bangalore, Karnataka, India
}

\begin{abstract}
Article Info

Volume 8, Issue 3

Page Number : 148-165

Publication Issue

May-June-2021

\section{Article History}

Accepted : 07 May 2021

Published : 17 May 2021

The study focuses on the influence and contribution of multi-walled CarbonNano tube (MWCNT) and boron carbide (B4C) to the tribological properties of copper matrix composites. The Samples are prepared using ultrasonic assisted stir casting for different weight fractions. The tribological properties like wear and corrosion studies been carried out according to ASTM standards. Wear rate increased with the increase in speed and load for every combination of the composite. However, with CNT being the main reinforcement with addition of CNT wear rate has reduced marginally. Addition of Boron Carbide also to some extent decreased the wear rate but CNT plays a major role in reducing the wear rate. Corrosion studies of the composite materials is carried out by Weight loss corrosion techniques, it is clearly evident from the critical analysis of the results that with the addition of reinforcements to the composite material, the corrosion rate in weight loss corrosion technique decreases drastically with the duration of time, this is due to the formation of a passive oxide layer on the composite specimen.
\end{abstract}

Keywords : Boron Carbide(B $\left.{ }_{4} \mathrm{C}\right)$, Multi-walled Carbon-Nano tube (MWCNT), Wear and Corrosion Rate.

\section{INTRODUCTION}

A composite material is a material made from two or more constituent materials with significantly different physical or chemical properties; when combined it produces a material with characteristics different from the individual. It consists of matrix and reinforcement; matrix is the bulk of material holding the reinforcement together in position. Fibers or particulates embedded in matrix of another material are the best example of modern-day composite materials. The individual component remains separate and distinct within the finished structure in macroscopic level. 
Composites are preferred more because of Lighter, Stronger, less expensive compared to traditional materials etc. Reinforcement is load bearing material and also provides additional properties like wear resistance, impact strength, corrosion resistance etc. Most commercially produced composite use polymer matrix often called as resin solutions. Most common polymers are polyester, vinyl ester, epoxy, phenolic, poly amide, polypropylene etc.

Reinforcement may be fibers, flakes, particulates or whiskers etc. while fibers are classified as natural fibers and man-made fibers.

Composites are usually man-made materials but can also be sometimes natural such as wood. They are mostly formed by the combination of two different materials separated by a distinct interface. The properties of a composite as a whole are enhanced as compared to the properties of its components. The two phases that make up a composite are known as reinforcing phase and matrix phase. The reinforcing phase is embedded in the matrix phase and mainly provides strength to the matrix. The reinforcing phases usually found in composites are particulates, fibers or sheets and the matrix materials can be of the form of polymers, ceramics or metals.

Composites are made up of individual materials referred to as constituent materials. There are two categories of constituent materials: matrix and reinforcement. At least one portion of each type is required. The matrix material surrounds and supports the reinforcement materials by maintaining their relative positions. The reinforcements impart their special mechanical and physical properties to enhance the matrix properties. A synergism produces material properties unavailable from the individual constituent materials, while the wide variety of matrix and strengthening materials allows the designer of the product or structure to choose an optimum combination.
A variety of moulding methods can be used according to the end-item design requirements. The principal factors impacting the methodology are the natures of the chosen matrix and reinforcement materials. Another important factor is the gross quantity of material to be produced. Large quantities can be used to justify high capital expenditures for rapid and automated manufacturing technology. Small production quantities are accommodated with lower capital expenditures but higher labour and tooling costs at a correspondingly slower rate.

Composites offer significant weight saving over existing metal hence used for Aircraft bodies. Composite materials for trusses and benches used in satellites for space applications. Since coefficient of linear thermal expansion is low compares to monolithic materials. Unidirectional fiber composites have specific tensile strength about 4 to 6 times greater than that of steel and aluminium.

The most important advantage associated with composites is their high strength and stiffness along with low weight. This high strength to weight ratio enables the greater usage of composites in space applications where being light and strong is given prime importance. Also, in composites the fibers present share the load applied and prevents the rapid propagation of cracks as in metals. Another advantage of composites is the flexibility associated with their designing method.

It is because they can be moulded to form various shapes be it easy or complex. Composites with proper composition and manufacturing can withstand corrosive and high temperature environments. With all these advantages it is obvious to think why the composites have not replaced the metals. One major drawback linked with the composites is its high cost which is often due to the use of expensive raw materials and not due to the manufacturing processes. 


\section{Classification of Composites}

Composite materials are commonly classified at following two distinct levels:

- matrix constituent

- reinforcement form

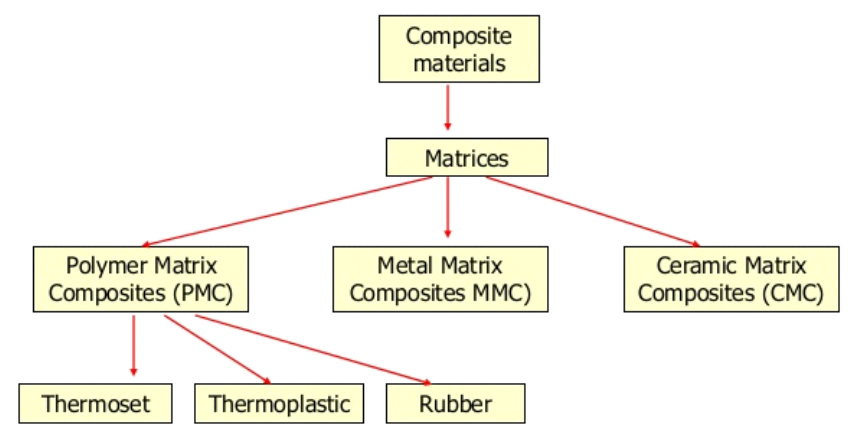

Figure 1.1 Classification based on matrix constituents.

There are two classification systems of composite materials. One of them is based on the matrix material (metal, ceramic, and polymer) and the second is based on the material structure:

\section{Classification of composites based on matrix material}

- $\quad$ Metal Matrix Composites (MMC): Metal Matrix Composites are composed of a metallic matrix (aluminium, magnesium, iron, cobalt, copper) and a dispersed ceramic (oxides, carbides) or metallic (lead, tungsten, molybdenum) phase.

- Ceramic Matrix Composites (CMC): Ceramic Matrix Composites are composed of a ceramic matrix and embedded fibers of other ceramic material (dispersed phase).

- Polymer Matrix Composites (PMC): Polymer Matrix Composites are composed of a matrix from thermoset (Unsaturated Polyester (UP), Epoxy (EP)) or thermoplastic (Polycarbonate (PC), Polyvinylchloride, Nylon, Polysterene) and embedded glass, carbon, steel or Kevlar fibers (dispersed phase).

\section{METHODS AND MATERIAL}

The methodology followed for the research work.

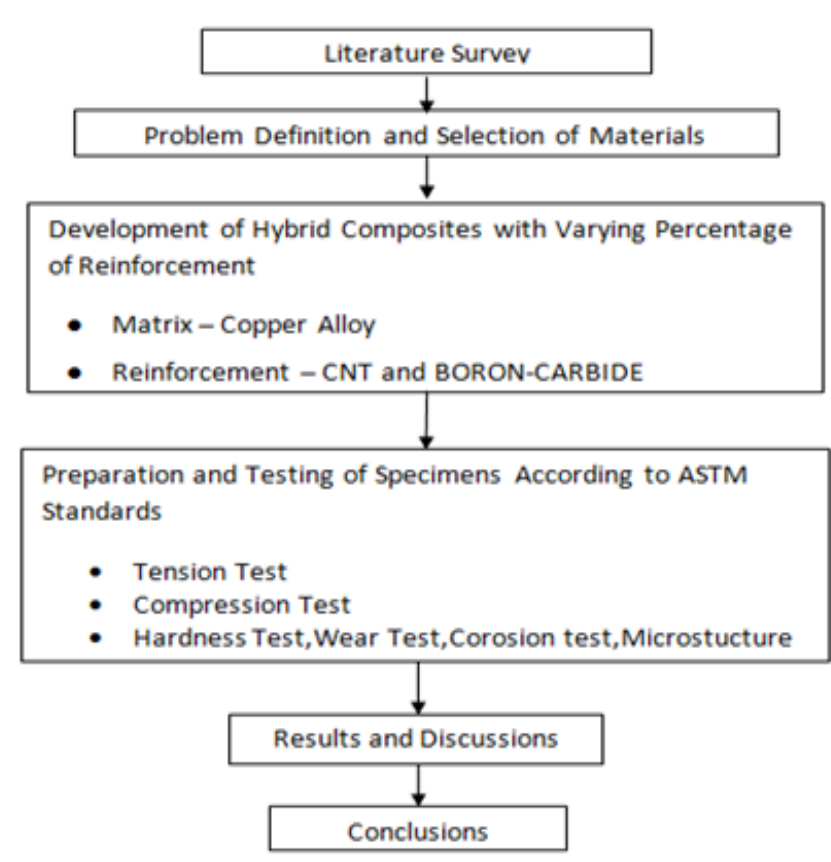

\section{- Materials Procurement}

The matrix and the reinforcement materials are procured from suppliers and the details are as mentioned in Table 1.1.

Table 1.1: Details of Material Procurement

\begin{tabular}{|c|c|c|}
\hline Material & Manufacturer/Suppliers & Quantity \\
\hline Copper & $\begin{array}{c}\text { Fenfee Metallurgicals, } \\
\text { Uttarahalli, Bangalore }\end{array}$ & $30 \mathrm{~kg}$ \\
\hline CNT & $\begin{array}{c}\text { Go Green Products, No. } \\
225 \mathrm{E}, 1^{\text {st }} \text { floor, Gandhi } \\
\text { Road Alwarthirunagar, } \\
\text { Chennai.-600087. }\end{array}$ & $500 \mathrm{~g}$ \\
\hline B4C & $\begin{array}{c}\text { Go Green Products No. } \\
225 \mathrm{E}, 1^{\text {st }} \text { floor, Gandhi } \\
\text { Road Alwarthirunagar, } \\
\text { Chennai.-600087. }\end{array}$ & \\
& $500 \mathrm{~g}$ \\
\hline
\end{tabular}

Reinforcement's compositions are selected based on the previous work done by many researchers. In many literatures authors have mentioned the reinforcement percentage should be less than $10 \%$ for Copper and $2 \%$ for CNT, if it is more than $10 \%$ reinforcement will not mix with the casting properly and there is a chance of agglomeration of particles. So, 
in the present study reinforcement compositions are limited to above mentioned weight percentage.

\section{- $\quad$ Copper(Cu)}

Copper is non-polymorphous metal with face centred cubic lattice zinc addition produces a yellow color, and nickel addition produces a silver colour. Melting temperature is $1083{ }^{\circ} \mathrm{C}$ and density is $8900 \mathrm{~kg} \cdot \mathrm{m}-3$, which is three times heavier than aluminium. The heat and electric conductivity of copper is lower compared to the silver, but it is 1.5 times larger compared to the aluminium.
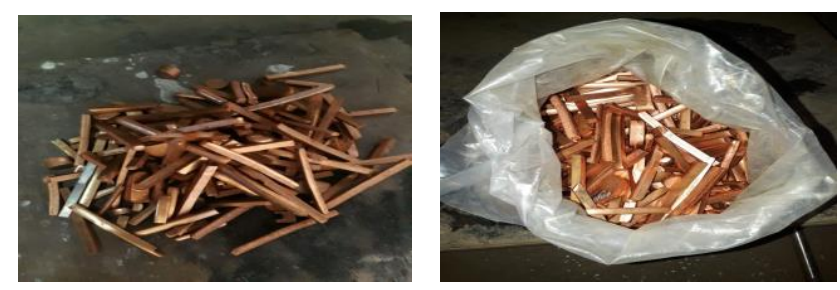

Figure1.2: Copper billets cut into small pieces

\section{- Carbon Nanotubes (CNT)}

Carbon nanotubes (CNTs) are procured from Go Green Products, these cylindrical carbon molecules have unusual properties, which are valuable for nanotechnology, electronics, optics and other fields of materials science and technology. In particular, owing to their extraordinary thermal conductivity and mechanical and electrical properties, carbon nanotubes find applications as additives to various structural materials.

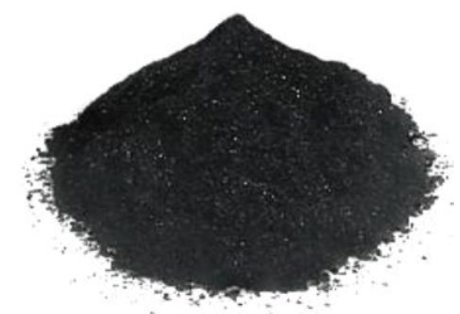

Figure 1.3: Carbon Nano Tubes (CNT)

\section{- Boron Carbide(B4C)}

Boron carbide is an extremely hard and covalent material used in tank or armour, bullet proof vests, engine sabotage powder as well numerous industrial applications. With a Vickers hardness of $>30 \mathrm{GPA}$, it is one of the hardest known materials, behind cubic boron nitride and diamond Boron carbide was discovered in 19th century as a by-product of reactions involving metal borides, but its chemical formula was unknown, Approximately B4C. The ability of boron carbide to absorb neutrons without forming long lived radionuclides makes it attractive as an absorbent for neutrons radiations arising in nuclear power plants and from antipersonnel-neutron bombs.

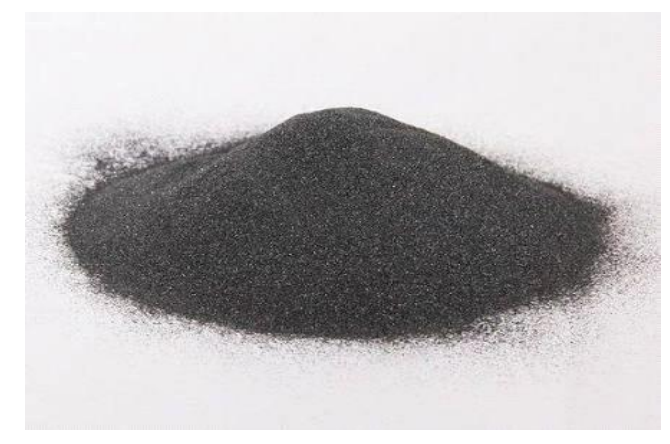

Figure 1.4: Boron carbide

\section{EXPERIMENT}

\section{FABRICATION OF TEST SPECIMENS.}

The microstructure of any material is a complex function of the casting process, subsequent cooling rates. Therefore, composites fabrication is one the most challenging and difficult task. Stir casting technique of liquid metallurgy was used to prepare Copper Alloy Composites.

\section{- $\quad$ Copper based MMC preparation by Stir Casting}

A stir casting setup as shown in Figure 1.5, Consist of a Coke fired Furnace and a stirrer assembly, which was used to synthesize the composite. Figure1.6 gives the schematic diagram of a typical stir casting setup.

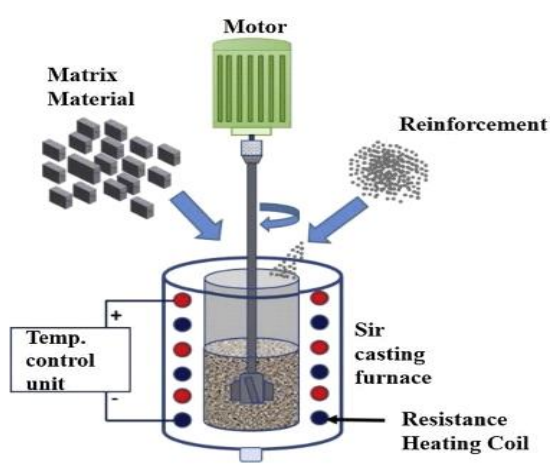

Figure. 1.5 Graphical representation of stir casting setup 


\section{- $\quad$ Composite Preparation Furnace}

A coal fired $10 \mathrm{~kg}$ capacity furnace was used for melting the Copper. Figure 4.9 is the picture of the melting furnace used for the present research work. The temperature range of the furnace is more than 20000 C. Figure 4.6 shows the Crucibles for pouring the molten metal and copper Ingots.

\section{Preheating of reinforcement}

Muffle furnace, was used to preheat the particulate to a temperature of $5000 \mathrm{C}$. It was maintained at that temperature till it was introduced into the copper and copper alloy melt. The preheating of reinforcement is necessary in order to reduce the temperature gradient and to improve wetting between the molten metal and the particulate reinforcement.

\section{- Melting of Matrix alloy}

The melting range of CU alloy is of $1000-10830 \mathrm{C}$. A known quantity of Copper ingots were loaded into the Graphite crucible of the furnace for melting. The melt was super-heated to a temperature above 15000C and maintained at that temperature.

The molten metal was then degassed using Hexo chloro ethane tablets for about $8 \mathrm{~min}$. Figure 1.6(b) and Figure 1.6(c) gives the photographic image of crucible and Molten Metal respectively.

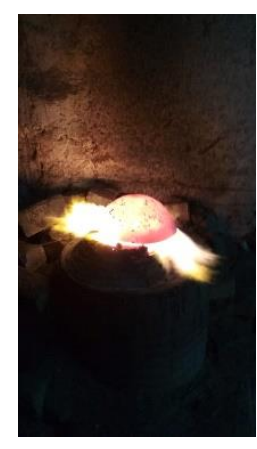

(a)

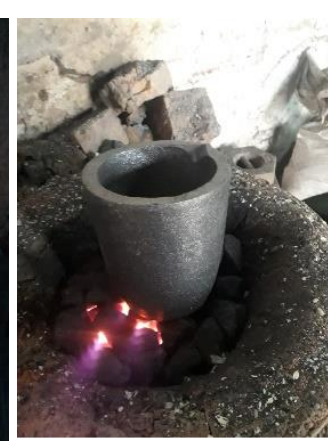

(b)

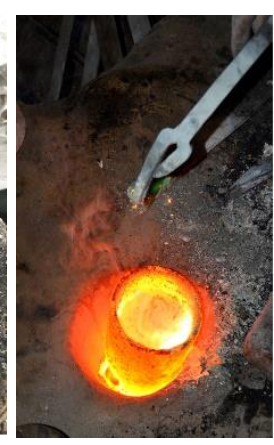

(c)
Fig 1.6 (a) External View of coal fired Furnace, (b) Crucibles, (c) Molten Metal

\section{- Mixing and Stirring}

Alumina coated stainless steel impeller was used to stir the molten metal to create a vortex. The impeller was of centrifugal type with 3 blades welded at 450 inclinations and 1200 apart. The stirrer was rotated at a speed of $300-400 \mathrm{rpm}$ and a vortex was created in the melt. The depth of immersion of the impeller was approximately one third of the height of the molten metal. From the bottom of the crucible. The preheated particulates of CNT and BORON CARBIDE were introduced into the vortex at the rate of $100 \mathrm{gm} / \mathrm{min}$. Figure 1.7(a) shows the process of adding reinforcing material Chopped $\mathrm{CNT}$ and B4C. Stirring was continued until interface interactions between the particles and the matrix promoted wetting. The melt was superheated to temperature of $15000 \mathrm{C}$ it was poured into the preheated die.

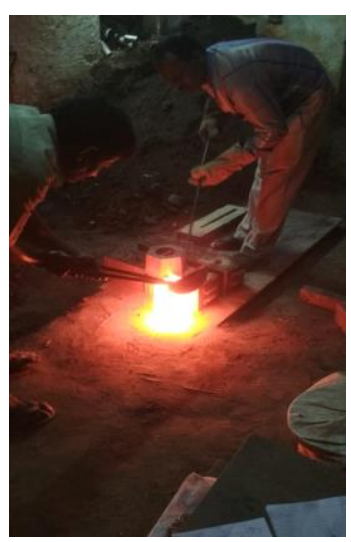

(a)

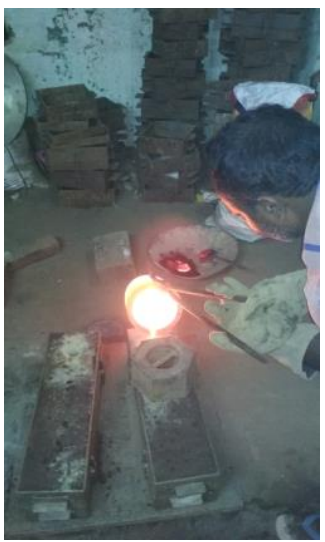

(b)
Fig 1.7 : (a) Reinforcement materials being added to the molten matrix, (b) Pouring Molten Metal into the mould

\subsection{MACHINING}

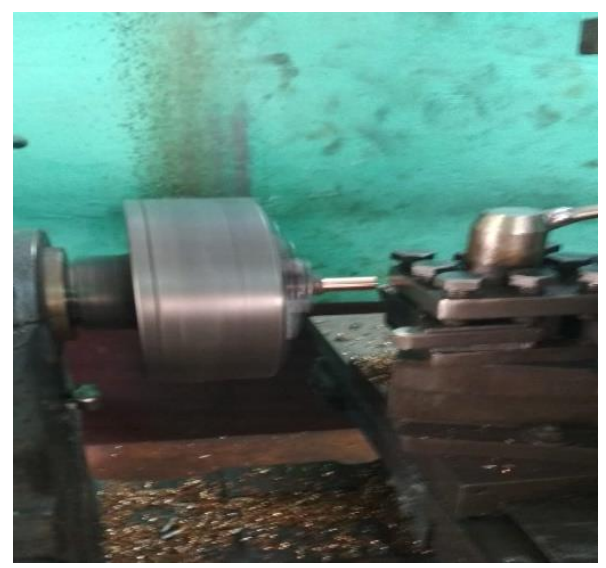

Figure : 1.8 Machining of Casted Product 
The casted specimens obtained were machined on a Lathe according to ASTM standards for Wear and Corrosion Tests.

The specimens are fabricated as per ASTM standards, as such the corrosion test specimens fabricated as per ASTM G 31 - 72 with $\varnothing 20 \mathrm{~mm}$ and length $20 \mathrm{~mm}$, wear test specimens as per ASTM G99 standards with a diameter of $6 \mathrm{~mm}$ and a length of $30 \mathrm{~mm}$.

\section{Composition of Specimens Prepared}

Table 1.2. Composition of developed Copper metal matrix composite.

\begin{tabular}{|c|c|c|c|}
\hline Specification & CNT\% & B4C\% & COPPER \% \\
\hline C & 0 & 0 & 100 \\
\hline C1 & 0.5 & 1 & 98.5 \\
\hline C2 & 0.5 & 3 & 96.5 \\
\hline C3 & 0.5 & 5 & 94.5 \\
\hline C4 & 1.0 & 1 & 98.0 \\
\hline C5 & 1.0 & 3 & 96.0 \\
\hline C6 & 1.0 & 5 & 94.0 \\
\hline C7 & 1.5 & 1 & 97.5 \\
\hline C8 & 1.5 & 3 & 95.5 \\
\hline C9 & 1.5 & 5 & 93.5 \\
\hline
\end{tabular}

\section{TESTING}

\section{Wear Test}

For the pin-on-disk wear test, two specimens are required. One, a pin with a reduced tip, is positioned perpendicular to the other, usually at a circular disk. A ball, rapidly held, is often used as the pin specimen. The test machine causes either the disk specimen or the pin specimen to revolve above the disk center. In either case, the sliding path is a circle on the disk surface. The plane of the disk may be oriented either horizontally or vertically.

- Wear results may differ for different orientations.
- Wear results may differ for different loading methods.

- Wear results are reported as volume loss in cubic millimetres for the pin and the disk separately. When two different materials are tested, it is recommended that each material be tested in both the pin and disk positions.

The amount of wear is determined by measuring appropriate linear dimensions of both specimens before and after the test, or by weighing both specimens before and after the test. If linear measures of wear are used, the length change or shape change of the pin, and the depth or shape change of the disk wear track(in millimeters) are determined by any suitable metrological technique, such as electronic distance stylus profiling. Linear measures of wear are converted to wear volume (in cubic millimeters) by using appropriate geometric relations. Linear measures of wear are used frequently in practice since mass loss is often too small to measure precisely. If loss of mass is measured, the mass loss value is converted to volume loss (in cubic millimeters) using an appropriate value for the specimen density.

- Wear results are usually obtained by conducting a test for a selected sliding distance and for selecting values of load and speed.

- Wear results may in some cases be reported as plots of wear volume versus sliding distances. Such plots may display non - linear relationships between wear volume and distance over certain portions of the total factors such as the applied load, machine characteristics, sliding speed, sliding distance, the environment and the material properties. The value of any wear test method lies in predicting the relative ranking of material combinations. Since the pin - on - disk test method does not attempt to duplicate all the conditions that may be experienced in service (for example; lubrication, pressure, load, contact geometry, removal of water debris and presence of 
corrosive environment), there is no ensure that the test will predict the wear rate of a given material under conditions differing from those in the test.

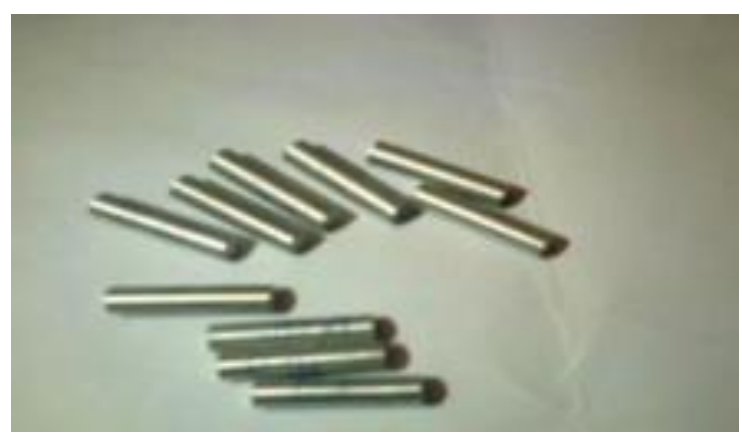

Figure1.9 Machined specimens for wear test

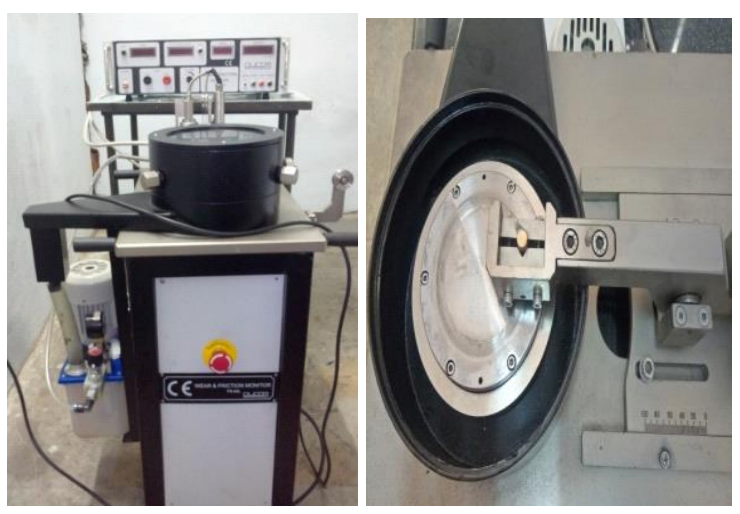

Figure 1.10 (a) and (b) - Pin on disc machine

\section{Corrosion Test}

The corrosion test was carried out using static immersion weight loss method as per Standards. The test specimens were machined into standards discs of $20 \mathrm{~mm}$ diameter and $20 \mathrm{~mm}$ thick. Before testing the specimen, the surfaces were ground with silicon carbide paper of 1000 grit size. After subsequent rinsing with water and acetone the specimens were weighed accurately to a hundredth of milligram accuracy before starting the test by the weight loss method.

\section{Procedure}

- Preparation of the alkaline and acidic solutions containing sodium chloride of different normalities and hydrochloric acid of different molarities.

- Immersion of the corrosion specimens in the solution for the required time.

- Removal and cleaning of the corroded specimens.

- The method used for preparing the different normal $\mathrm{NaCl}$ and different molar $\mathrm{HCl}$ solutions was by volumetric analysis. Volumetric analysis is a method of quantitative analysis involving measurement of volumes of the reacting solutions. The volume of a standard solution required to react completely with a known volume of another solution is determined experimentally. From this normality of the other solution may be calculated.

- Preparation of Solution:

- The corrosion specimens were weighed on an electronic weighing machine accurately up to the fourth decimal place. Each of the specimens immersed in $200 \mathrm{ml}$ of solution such that composites of the same composition are immersed of $0.5 \mathrm{~N}, 1.0 \mathrm{~N} \mathrm{NaCl}$ solutions and $0.5 \mathrm{M}, 1.0 \mathrm{M} \mathrm{HCl}$ for test durations of 24,48,72 and 96 hours.

- Removal and surface cleaning of the corroded specimens:

- The specimens are removed from their respective solutions at the end of their respective time durations. They are then immersed in Clark's solution for 10 minutes and gently cleaned with a soft brush to remove adhered scales. After drying thoroughly, the specimens were weighed again.

\section{RESULTS AND DISCUSSION}

The composites fabricated are evaluated for characteristics like Wear and Corrosion for different weight percentages of CNT and boron carbide in copper alloy. The present work attempts to understand the influence of reinforcements on the matrix alloy.

Figures and tables show the effect of CNT and B4Creinforcements on the various Tribological properties of all alloy composites. 


\section{- Wear Test Results}

Wear test results were calculated for various load and different RPM speed.

Table 1.2 Wear Rates at 10N load and different RPM

\begin{tabular}{|c|c|c|c|c|}
\hline \multirow{3}{*}{$\begin{array}{c}\text { Models/Wear } \\
\text { Rate }(\mu \mathrm{m})\end{array}$} & \multicolumn{4}{|c|}{ LOAD (10N) } \\
\cline { 2 - 5 } & $\mathbf{2 0 0}$ & $\mathbf{3 0 0}$ & $\mathbf{4 0 0}$ & $\mathbf{5 0 0}$ \\
& RPM & RPM & RPM & RPM \\
\hline C1 & 490 & 580 & 965 & 1215 \\
\hline C2 & 387 & 460 & 475 & 654 \\
\hline C3 & 289 & 352 & 382 & 457 \\
\hline C4 & 376 & 504 & 881 & 921 \\
\hline C5 & 264 & 337 & 371 & 465 \\
\hline C6 & 141 & 227 & 312 & 368 \\
\hline C7 & 287 & 421 & 784 & 832 \\
\hline C8 & 207 & 278 & 291 & 345 \\
\hline C9 & 125 & 171 & 157 & 180 \\
\hline
\end{tabular}

Table 1.3 Wear Rates at 20N load and different RPM

\begin{tabular}{|c|l|l|l|l|}
\hline \multirow{2}{*}{$\begin{array}{c}\text { Models/Wear } \\
\text { Rate }(\mu \mathrm{m})\end{array}$} & \multicolumn{4}{|c|}{ LOAD (20N) } \\
\cline { 2 - 5 } & $\begin{array}{c}200 \\
\text { RPM }\end{array}$ & $\begin{array}{c}300 \\
\text { RPM }\end{array}$ & $\begin{array}{c}400 \\
\text { RPM }\end{array}$ & $\begin{array}{c}500 \\
\text { RPM }\end{array}$ \\
\hline C1 & 762 & 784 & 985 & 1240 \\
\hline C2 & 422 & 458 & 481 & 668 \\
\hline C3 & 476 & 481 & 501 & 548 \\
\hline C4 & 645 & 698 & 784 & 954 \\
\hline C5 & 268 & 347 & 451 & 481 \\
\hline C6 & 302 & 353 & 452 & 460 \\
\hline C7 & 502 & 527 & 584 & 656 \\
\hline C8 & 168 & 189 & 280 & 308 \\
\hline C9 & 188 & 201 & 291 & 327 \\
\hline
\end{tabular}

Table 1.4 Wear Rates at 30N load and different RPM

\section{Models/Wear $\quad$ LOAD (30N)}

\begin{tabular}{|c|l|l|l|l|}
\hline \multirow{2}{*}{ Rate $(\mu \mathrm{m})$} & \multicolumn{4}{|c|}{ Speed (RPM) } \\
\cline { 2 - 5 } & $\begin{array}{c}200 \\
\text { RPM }\end{array}$ & $\begin{array}{c}300 \\
\text { RPM }\end{array}$ & $\begin{array}{c}400 \\
\text { RPM }\end{array}$ & $\begin{array}{c}500 \\
\text { RPM }\end{array}$ \\
\hline C1 & 922 & 974 & 1020 & 1157 \\
\hline C2 & 528 & 562 & 584 & 598 \\
\hline C3 & 484 & 501 & 517 & 557 \\
\hline C4 & 721 & 736 & 854 & 884 \\
\hline C5 & 411 & 455 & 479 & 447 \\
\hline C6 & 385 & 397 & 431 & 419 \\
\hline C7 & 631 & 649 & 689 & 684 \\
\hline C8 & 239 & 288 & 305 & 314 \\
\hline C9 & 198 & 225 & 257 & 268 \\
\hline
\end{tabular}

10N 200 RPM

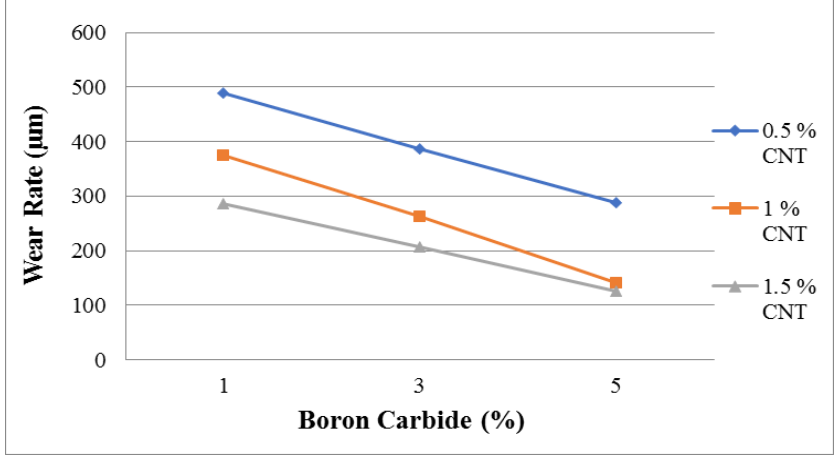

Figure:1.11 Effect of B4C and CNT on Wear Rate at $10 \mathrm{~N}$ load at $200 \mathrm{RPM}$

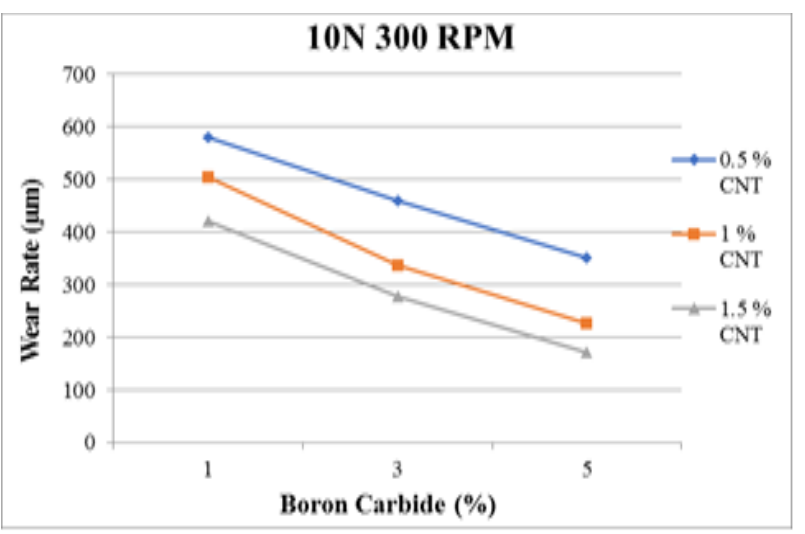

Figure:1.12 Effect of B4c And Cnt On Wear Rate At 10n Load At 300 Rpm

As seen in above graph, the wear rate decrease as the percentage of Boron Carbide increases from $1 \%, 3 \%$, and $5 \%$ and $0.5 \%, 1.0 \%$ and $1.5 \%$ CNT in CNT and Boron Carbide hybrid reinforced Copper based MMC. 
At $10 \mathrm{~N}$ load and $300 \mathrm{rpm}$ at track diameter of $100 \mathrm{~mm}$ in pin on disc experiment, this is because above the critical load, transition to severe wear occurs in unreinforced matrix alloy. But the reinforced MMCs have superior wear resistance

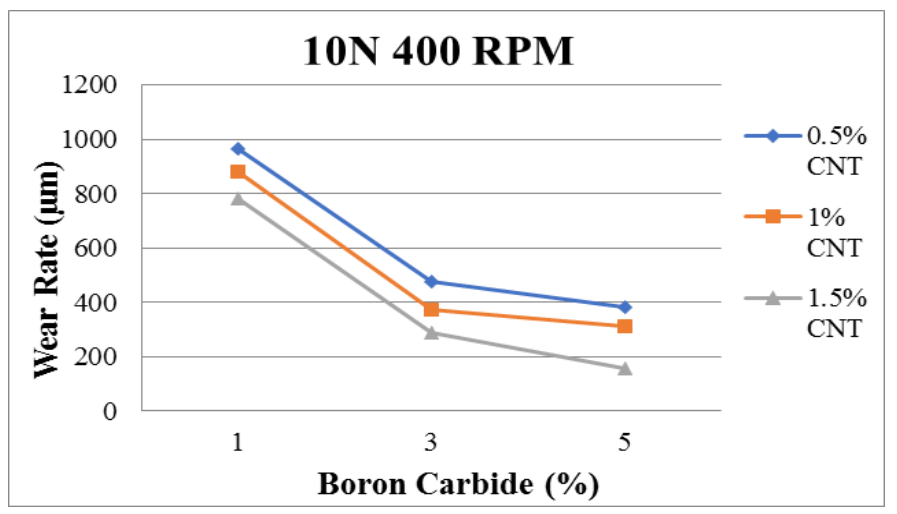

Figure:1.13 Effect of $\mathrm{B}_{4} \mathrm{C}$ and $\mathrm{CNT}$ on Wear Rate at $10 \mathrm{~N}$ load at $400 \mathrm{RPM}$

As seen in above graph, the wear rate decrease as the percentage of Boron Carbide increases from 1\%, 3\%, and $5 \%$ and $0.5 \%, 1.0 \%$ and $1.5 \%$ CNT in CNT and Boron Carbide hybrid reinforced Copper based MMC. At $10 \mathrm{~N}$ load and $400 \mathrm{rpm}$ at track diameter of $100 \mathrm{~mm}$ in pin on disc experiment, this is because improvement in wear resistance of the composites at low loads is attributed due to the presence of reinforcement, which form a thin film at the contact surface between the composite and the counter face.

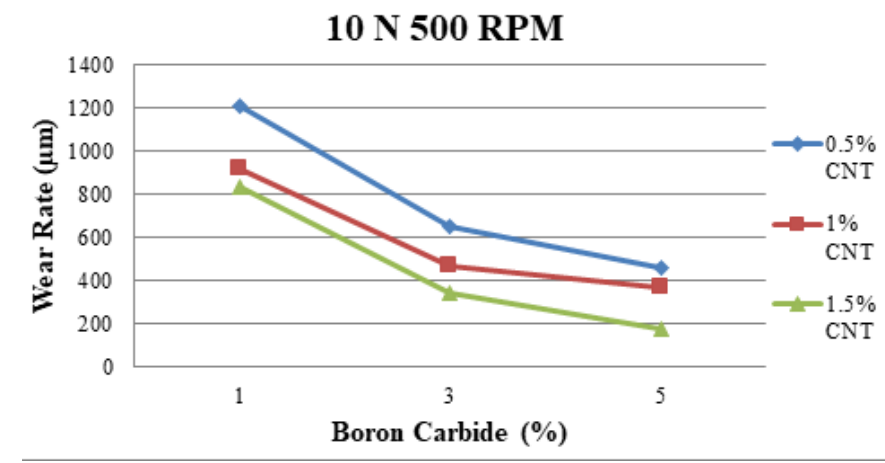

Figure:1.14 Effect of B4C and CNT on Wear Rate at $10 \mathrm{~N}$ load at $500 \mathrm{RPM}$

As seen in above graph, the wear rate decrease as the percentage of Boron Carbide increases from 1\%, $3 \%$, and $5 \%$ and $0.5 \%, 1.0 \%$ and $1.5 \%$ CNT in CNT and
Boron Carbide hybrid reinforced Copper based MMC. At $10 \mathrm{~N}$ load and $500 \mathrm{rpm}$ at track diameter of $100 \mathrm{~mm}$ in pin on disc experiment, this is because the significant improvement in the wear resistance of the composites in the present case may also be due to the type of the reinforcement used.

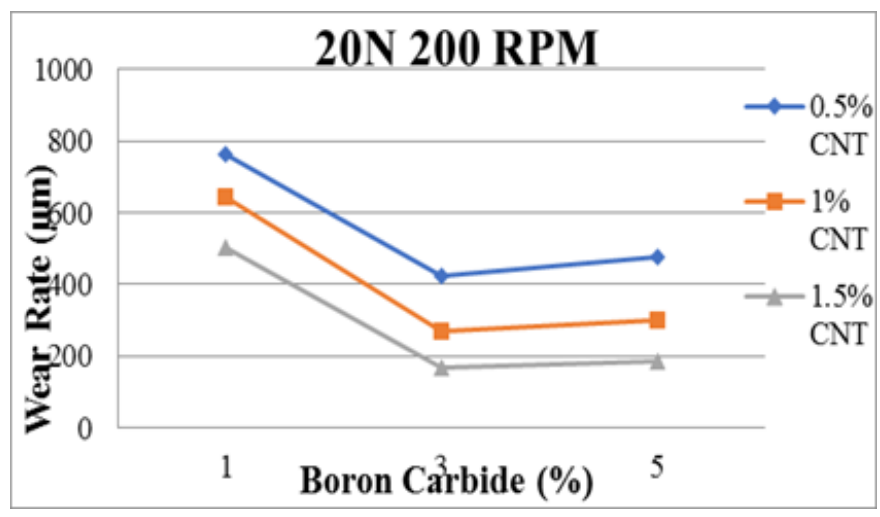

Figure:1.15 Effect of B4C and CNT on Wear Rate at $20 \mathrm{~N}$ load at $200 \mathrm{RPM}$

As seen in above graph, the wear rate decrease as the percentage of Boron Carbide increases from $1 \%$, $3 \%$, and $5 \%$ and $0.5 \%, 1.0 \%$ and $1.5 \%$ CNT in CNT and Boron Carbide hybrid reinforced Copper based MMC. At 20N load and 200rpm at track diameter of $100 \mathrm{~mm}$ in pin on disc experiment, this is because the type of the reinforcement is also a very important contributor to the wear behavior of the hybrid composites.

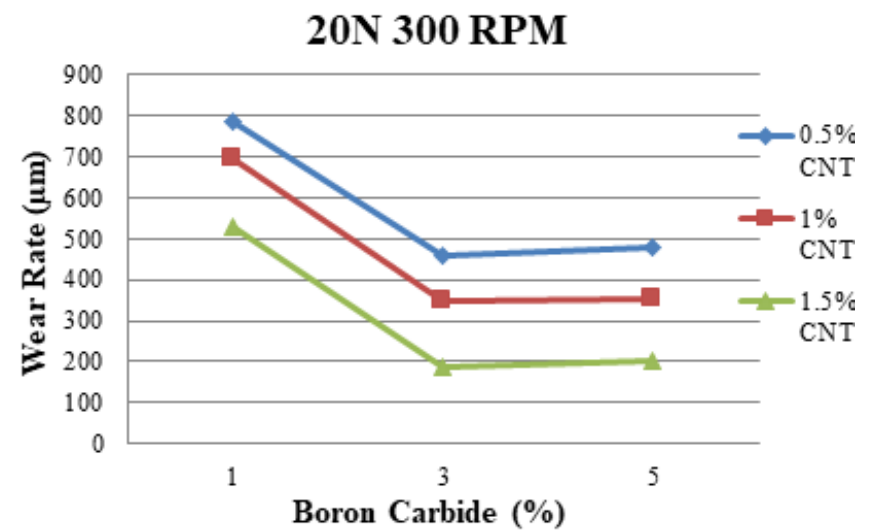

Figure:1.16. Effect of B4C and CNT on Wear Rate at $20 \mathrm{~N}$ load at $300 \mathrm{RPM}$ 
As seen in above graph, the wear rate decrease as the percentage of Boron Carbide increases from $1 \%$, $3 \%$, and $5 \%$ and $0.5 \%, 1.0 \%$ and $1.5 \%$ CNT in CNT and Boron Carbide hybrid reinforced Copper based MMC. At 20N load and 300rpm at track diameter of $100 \mathrm{~mm}$ in pin on disc experiment, this is because of increase in the amount of reinforcements in MMC. The critical load, transition to severe wear occurs in unreinforced matrix alloy. But the reinforced MMCs have superior wear resistance.

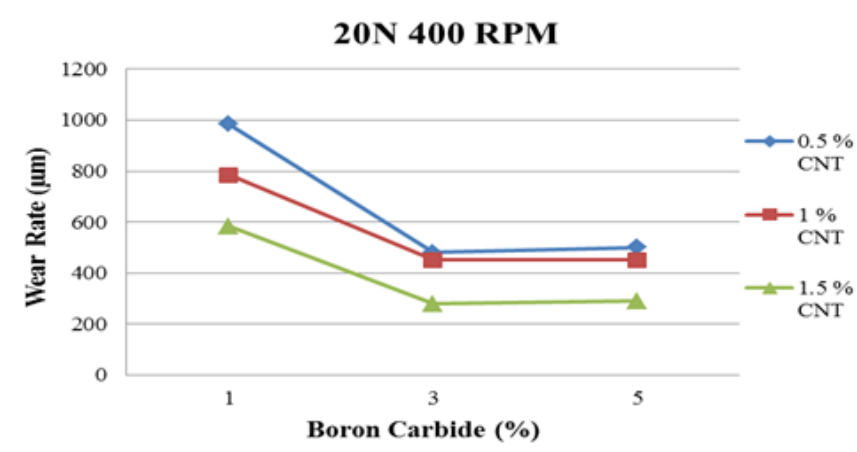

Figure:1.17 Effect of $\mathrm{B}_{4} \mathrm{C}$ and CNT on Wear Rate at $20 \mathrm{~N}$ load at $400 \mathrm{RPM}$

As seen in above graph, the wear rate decrease as the percentage of Boron Carbide increases from $1 \%$, $3 \%$, and $5 \%$ and $0.5 \%, 1.0 \%$ and $1.5 \%$ CNT in CNT and Boron Carbide hybrid reinforced Copper based MMC. At $20 \mathrm{~N}$ load and 400rpm at track diameter of $100 \mathrm{~mm}$ in pin on disc experiment, this is because of increase in the amount of reinforcements in MMC. The beneficial effect of the reinforcement on the wear resistance of composites is observed to be the best at low loads, which reduces with the increase in load applied.
20N 500 RPM

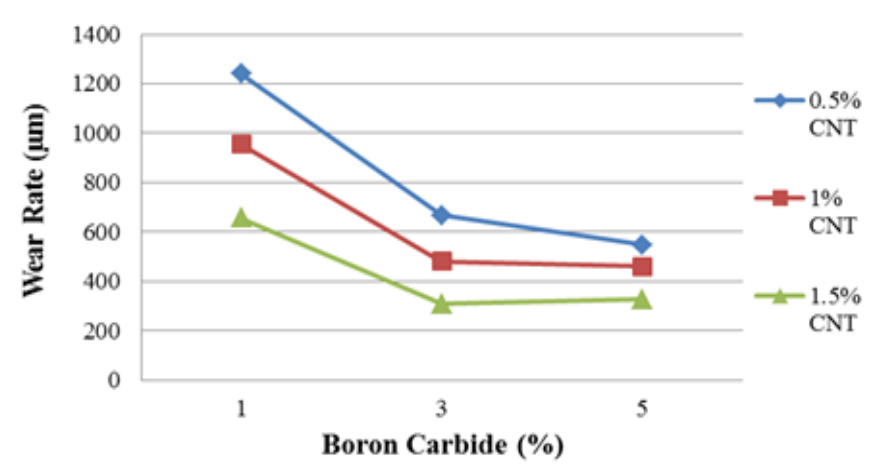

Figure:1.18 Effect of B4C and CNT on Wear Rate at $20 \mathrm{~N}$ load at $500 \mathrm{RPM}$

As seen in above graph, the wear rate decrease as the percentage of Boron Carbide increases from 1\%, 3\%, and $5 \%$ and $0.5 \%, 1.0 \%$ and $1.5 \%$ CNT in CNT and Boron Carbide hybrid reinforced Copper based MMC. At $20 \mathrm{~N}$ load and 500rpm at track diameter of $100 \mathrm{~mm}$ in pin on disc experiment, this is because of increase in the amount of reinforcements in MMC.

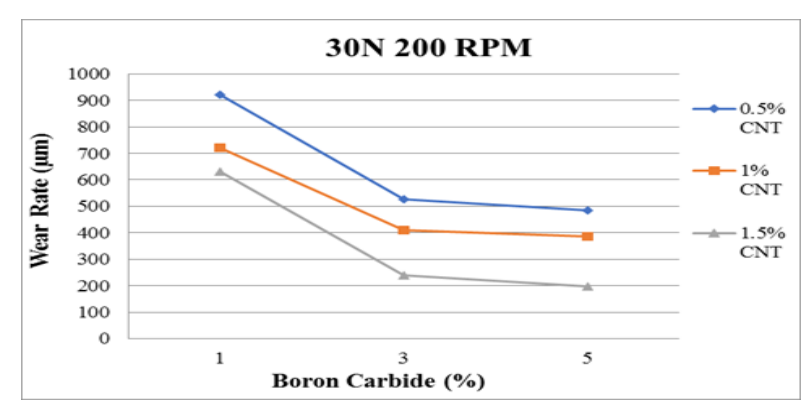

Figure:1.19 Effect of B4C and CNT on Wear Rate at $30 \mathrm{~N}$ load at $200 \mathrm{RPM}$

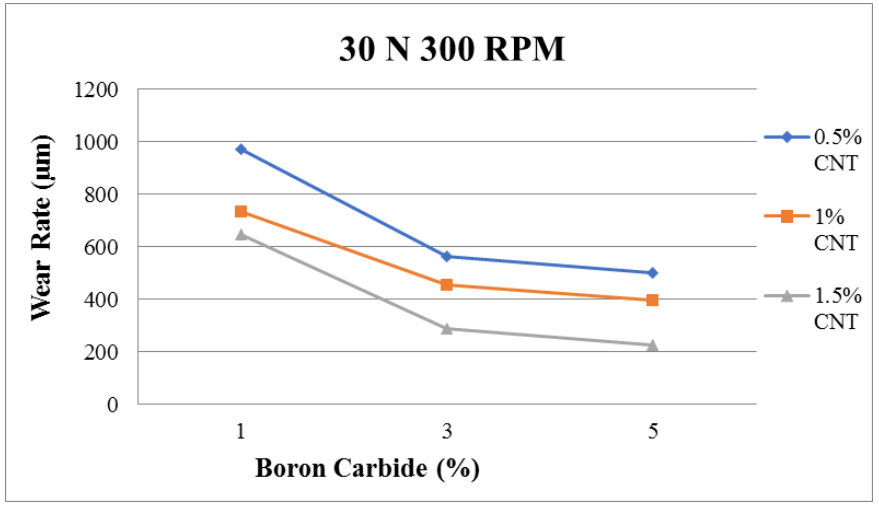


Dr. Tukaram Jadhav et al Int J Sci Res Sci \& Technol. May-June-2021, 8 (3) : 148-165

Figure : 1.20 Effect of $\mathrm{B}_{4} \mathrm{C}$ and $\mathrm{CNT}$ on Wear Rate at $30 \mathrm{~N}$ load at $300 \mathrm{RPM}$

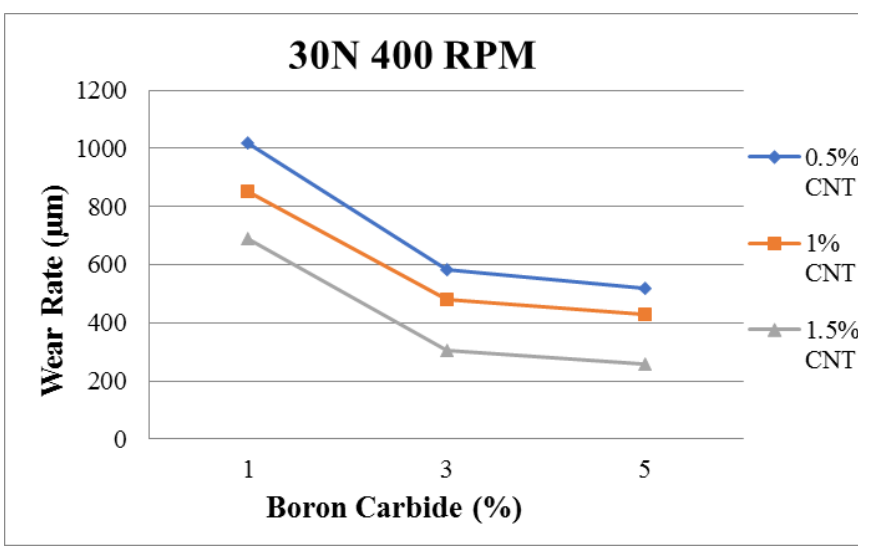

Figure:1.21 Figure:1.20 Effect of $\mathrm{B}_{4} \mathrm{C}$ and $\mathrm{CNT}$ on Wear Rate at 30N load at $400 \mathrm{RPM}$

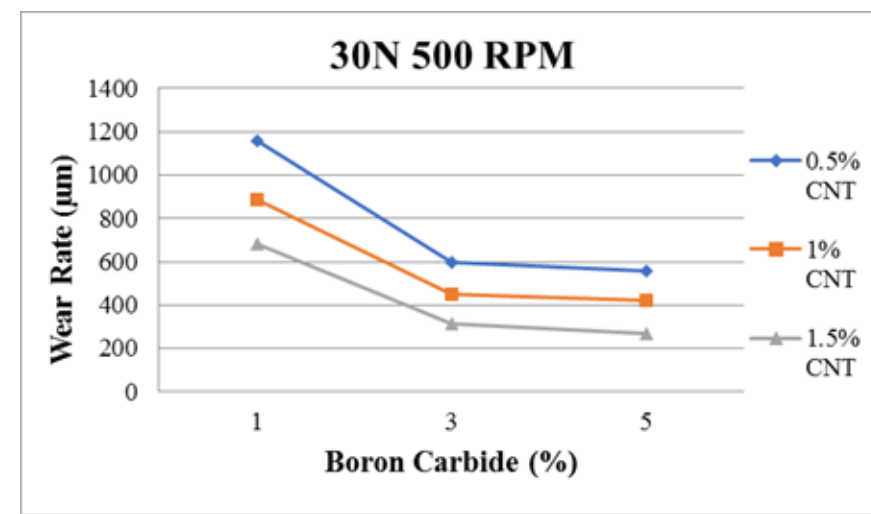

Figure:1.22 Figure:1.20 Effect of $\mathrm{B}_{4} \mathrm{C}$ and CNT on Wear Rate at $30 \mathrm{~N}$ load at $500 \mathrm{RPM}$

As seen in above graph, the wear rate decrease as the percentage of Boron Carbide increases from 1\%, 3\%, and $5 \%$ and $0.5 \%, 1.0 \%$ and $1.5 \%$ CNT in CNT and Boron Carbide hybrid reinforced Copper based MMC. At $30 \mathrm{~N}$ load and 500rpm at track diameter of $100 \mathrm{~mm}$ in pin on disc experiment, this is because, the type of the reinforcement is also a very important contributor to the wear behaviour of the hybrid composites.

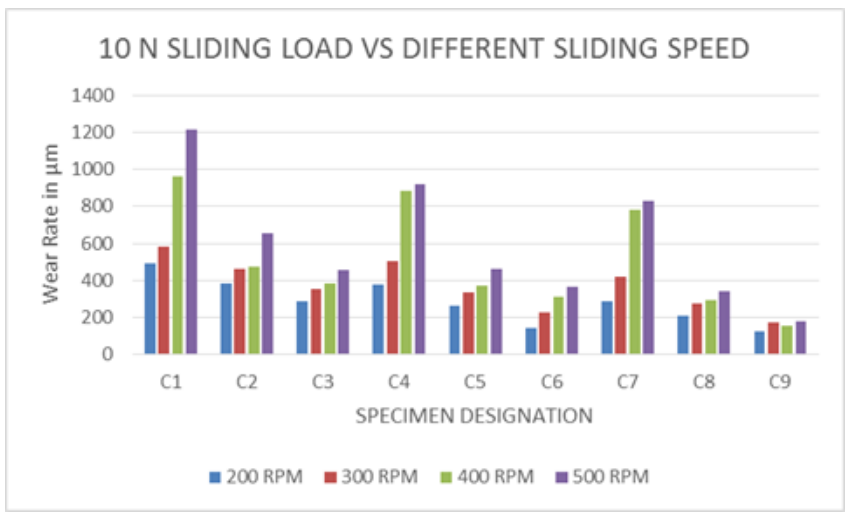

Figure : 1.23 Wear Rate at $10 \mathrm{~N}$ sliding load and different speed

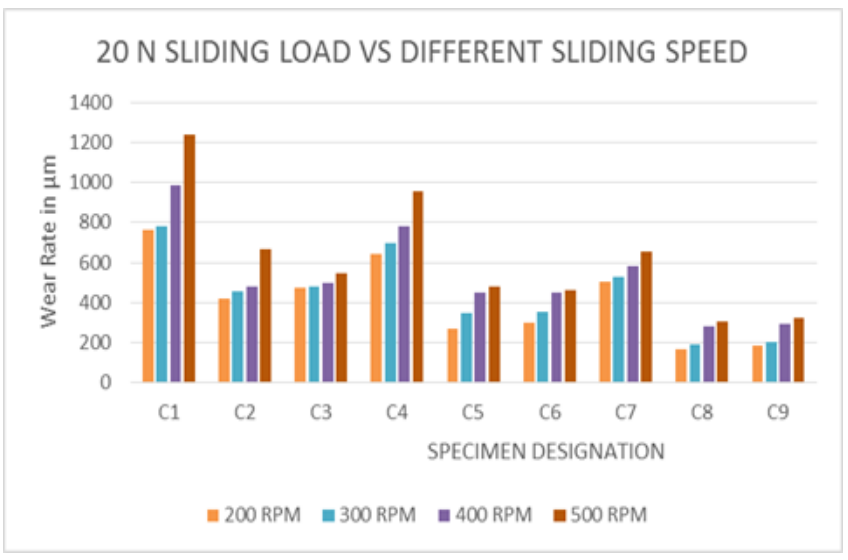

Figure : 1.24 Wear Rate at 10N sliding load and different speed

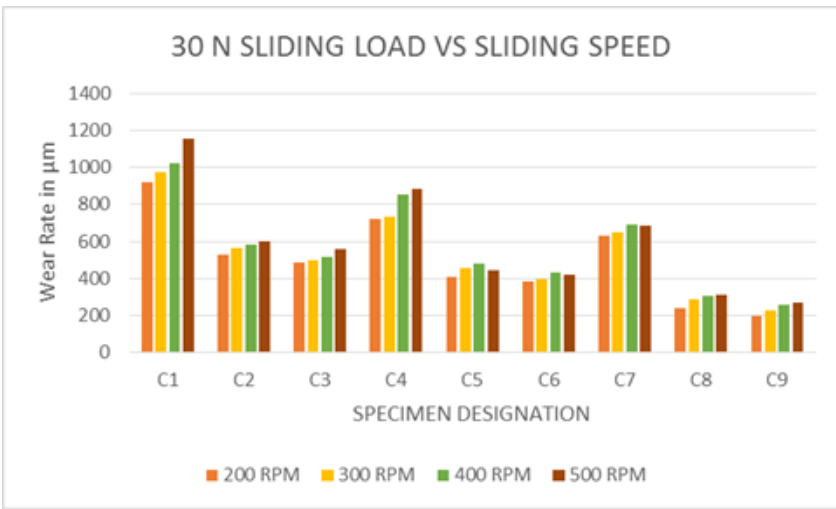

Figure : 1.25 Wear Rate at 30N sliding load and different speed

Figure 1.23, $1.24 \& 1.25$ Effect on Sliding speed $(200,300,400 \& 500 \mathrm{rpm})$ in the wear rate of hybrid composites at 10, 20 and $30 \mathrm{~N}$ load. Incorporation of reinforcements CNT and B4C to Copper matrix effects 
in less wear rate under various speed conditions. Wear rate is diminished because of fortification particles spreads on the outside of pin and development by ensuring layer in hybrid metal matrix composites when contrasted with copper. The sliding speed increase that causes ineffective contact between the surface of the hybrid composite which results reduction in wear rate.

\section{- Corrosion Test Results}

The weight loss corrosion test is carried out by suspending the specimen of dimension ( $\left.\phi 20{ }^{*} \mathrm{~L} 20\right)$ $\mathrm{mm}$ in 1 Molar Solution of acidic and alkaline medium of $\mathrm{HCl}$ and $\mathrm{NaOH}$ respectively, the specimens are initially weighed on a weigh scale of $0.1 \mathrm{mg}$ accuracy and then suspended in the corrosive medium for a duration of 24 hours, 48 hours, 72 hours and 96 hours respectively, after which the specimen is taken out from the corrosive medium and weighed to determine the weight loss by weighing it again in an electronic balance before calculating the corrosion rate using the formulae $\mathrm{CR}=\mathrm{K} \cdot \mathrm{W} \cdot \mathrm{A} \cdot \mathrm{D} \cdot \mathrm{T}$.

The graphs for 1 Molar $\mathrm{HCl}$ and $\mathrm{NaOH}$ are plotted based on the values thus obtained and critically examined. From the critical analysis of the values it is clearly evident that the corrosion rate decreases over a period of time and reaches its minimal value at the end of 96 hours of corrosion studies. Further the addition of CNT and B4C diminishes the corrosion in the specimens thereby enhancing its validity to be reinforced in the copper alloy for improving its corrosion resistance, In addition to the above, the addition of reinforcements forms a passive layer on the surface that will eventually avoid corrosion and facilitate the use of copper matrix composites in naval, aerospace and automobile applications. The corrosion rate decreases from 0.14 for C Specimen to 0.03 for C6 Specimen in acidic medium, while the corrosion rate decreases from 0.145 for C Specimen to 0.04 for C6 Specimen in alkaline medium.
Table: 1.5 Corrosion Rates at $0.5 \mathrm{~N}$ and $1 \mathrm{~N} \mathrm{NaCl}$ in $\mathrm{mm} / \mathrm{y}$

\begin{tabular}{|c|c|c|c|c|c|c|c|c|c|c|c|}
\hline \multirow{2}{*}{\multicolumn{2}{|c|}{\begin{tabular}{|l|l}
$\mathrm{Ti}$ \\
$\mathrm{m}$ \\
$\mathrm{e}$ \\
(H \\
$\mathrm{rs})$
\end{tabular}}} & \multicolumn{10}{|c|}{ CORROSION RATE (mm/y) } \\
\hline & & C & $\begin{array}{l}C \\
1\end{array}$ & $\begin{array}{l}C \\
2\end{array}$ & $\begin{array}{l}C \\
3\end{array}$ & $\begin{array}{l}C \\
4\end{array}$ & $\begin{array}{l}C \\
5\end{array}$ & $\begin{array}{l}C \\
6\end{array}$ & $\begin{array}{l}C \\
7\end{array}$ & $\begin{array}{l}C \\
8\end{array}$ & C9 \\
\hline & $\begin{array}{l}2 \\
4\end{array}$ & $\begin{array}{c}0 . \\
09 \\
87\end{array}$ & $\begin{array}{c}0 . \\
08 \\
48\end{array}$ & $\begin{array}{c}0 . \\
07 \\
16\end{array}$ & $\begin{array}{c}0 . \\
06 \\
76\end{array}$ & $\begin{array}{c}0 . \\
06 \\
18\end{array}$ & $\begin{array}{c}0 . \\
05 \\
05\end{array}$ & $\begin{array}{c}0 . \\
04 \\
1\end{array}$ & $\begin{array}{c}0 . \\
03 \\
56\end{array}$ & $\begin{array}{c}0 . \\
02 \\
74\end{array}$ & $\begin{array}{l}0 . \\
01 \\
81\end{array}$ \\
\hline 0 & $\begin{array}{l}4 \\
8\end{array}$ & $\begin{array}{c}0 . \\
06 \\
48\end{array}$ & $\begin{array}{l}0 . \\
05 \\
75\end{array}$ & $\begin{array}{c}0 . \\
04 \\
51\end{array}$ & $\begin{array}{c}0 . \\
03 \\
66\end{array}$ & $\begin{array}{l}0 . \\
03 \\
27\end{array}$ & $\begin{array}{c}0 . \\
02 \\
09\end{array}$ & $\begin{array}{l}0 . \\
01 \\
88\end{array}$ & $\begin{array}{l}0 . \\
01 \\
39\end{array}$ & $\begin{array}{c}0 . \\
01 \\
19\end{array}$ & $\begin{array}{l}0 . \\
01 \\
04\end{array}$ \\
\hline 5 & $\begin{array}{l}7 \\
2\end{array}$ & $\begin{array}{c}0 . \\
04 \\
86\end{array}$ & $\begin{array}{c}0 . \\
03 \\
44\end{array}$ & $\begin{array}{c}0 . \\
02 \\
68\end{array}$ & $\begin{array}{c}0 . \\
02 \\
1\end{array}$ & $\begin{array}{c}0 . \\
02\end{array}$ & $\begin{array}{c}0 . \\
01 \\
32\end{array}$ & $\begin{array}{c}0 . \\
01 \\
12\end{array}$ & $\begin{array}{c}0 . \\
01 \\
05\end{array}$ & $\begin{array}{c}0 . \\
00 \\
85\end{array}$ & $\begin{array}{c}0 . \\
00 \\
56\end{array}$ \\
\hline $\mathbf{N}$ & $\begin{array}{l}9 \\
6\end{array}$ & $\begin{array}{c}0 . \\
03 \\
75\end{array}$ & $\begin{array}{c}0 . \\
03 \\
14\end{array}$ & $\begin{array}{c}0 . \\
02 \\
71\end{array}$ & $\begin{array}{c}0 . \\
02 \\
13\end{array}$ & $\begin{array}{c}0 . \\
01 \\
89\end{array}$ & $\begin{array}{c}0 . \\
01 \\
16\end{array}$ & $\begin{array}{c}0 . \\
00 \\
98\end{array}$ & $\begin{array}{c}0 . \\
00 \\
86\end{array}$ & $\begin{array}{c}0 . \\
00 \\
43\end{array}$ & $\begin{array}{c}0 . \\
00 \\
32 \\
5\end{array}$ \\
\hline & $\begin{array}{l}2 \\
4\end{array}$ & $\begin{array}{c}0 . \\
18 \\
16\end{array}$ & $\begin{array}{l}0 . \\
16 \\
68\end{array}$ & $\begin{array}{l}0 . \\
15 \\
05\end{array}$ & $\begin{array}{l}0 . \\
14 \\
21\end{array}$ & $\begin{array}{c}0 . \\
12 \\
38\end{array}$ & $\begin{array}{c}0 . \\
10\end{array}$ & $\begin{array}{c}0 . \\
08 \\
23\end{array}$ & $\begin{array}{c}0 . \\
06\end{array}$ & $\begin{array}{c}0 . \\
04\end{array}$ & $\begin{array}{l}0 . \\
03 \\
01\end{array}$ \\
\hline 1 & $\begin{array}{l}4 \\
8\end{array}$ & $\begin{array}{c}0 . \\
16 \\
25\end{array}$ & $\begin{array}{c}0 . \\
14 \\
89\end{array}$ & $\begin{array}{c}0 . \\
13 \\
22\end{array}$ & $\begin{array}{l}0 . \\
11 \\
54\end{array}$ & $\begin{array}{c}0 . \\
09 \\
72\end{array}$ & $\begin{array}{c}0 . \\
08 \\
01\end{array}$ & $\begin{array}{c}0 . \\
06 \\
31\end{array}$ & $\begin{array}{c}0 . \\
04 \\
25\end{array}$ & $\begin{array}{c}0 . \\
02 \\
89\end{array}$ & $\begin{array}{l}0 . \\
01 \\
46\end{array}$ \\
\hline 0 & $\begin{array}{l}7 \\
2\end{array}$ & $\begin{array}{c}0 . \\
13 \\
25\end{array}$ & $\begin{array}{c}0 . \\
12 \\
14\end{array}$ & $\begin{array}{c}0 . \\
11 \\
24\end{array}$ & $\begin{array}{c}0 . \\
09 \\
73\end{array}$ & $\begin{array}{c}0 . \\
07 \\
48\end{array}$ & $\begin{array}{c}0 . \\
05 \\
41\end{array}$ & $\begin{array}{c}0 . \\
03 \\
12\end{array}$ & $\begin{array}{c}0 . \\
02 \\
19\end{array}$ & $\begin{array}{c}0 . \\
01 \\
55\end{array}$ & $\begin{array}{l}0 . \\
00 \\
92\end{array}$ \\
\hline & $\begin{array}{l}9 \\
6\end{array}$ & $\begin{array}{c}0 . \\
10 \\
86\end{array}$ & $\begin{array}{c}0 . \\
09 \\
24\end{array}$ & $\begin{array}{c}0 . \\
08 \\
19\end{array}$ & $\begin{array}{c}0 . \\
06 \\
88\end{array}$ & $\begin{array}{c}0 . \\
05 \\
01\end{array}$ & $\begin{array}{c}0 . \\
03 \\
56\end{array}$ & $\begin{array}{c}0 . \\
02 \\
24\end{array}$ & $\begin{array}{c}0 . \\
01 \\
12\end{array}$ & $\begin{array}{c}0 . \\
00 \\
98\end{array}$ & $\begin{array}{l}0 . \\
00 \\
21\end{array}$ \\
\hline
\end{tabular}




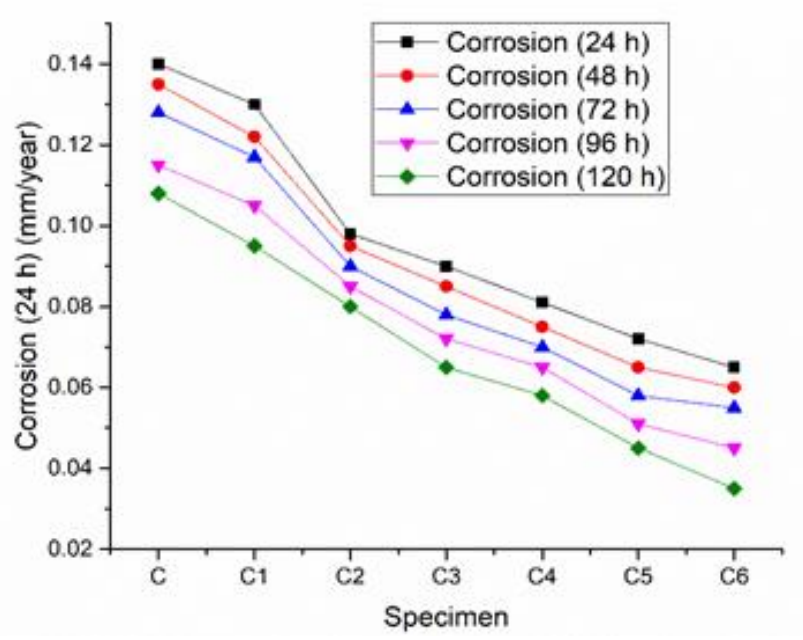

Figure : 1.26 Weight loss corrosion for different specimens $(1 \mathrm{M} \mathrm{HCl})$

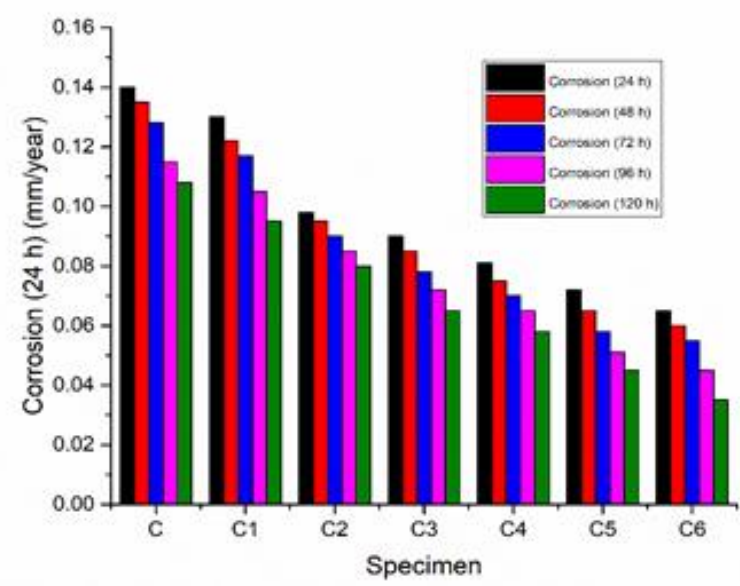

Figure : 1.27 Comparison of Weight loss corrosion for different specimens $(1 \mathrm{M} \mathrm{HCl})$

Table: 1.6 Corrosion Rates at $0.5 \mathrm{M}$ and $1 \mathrm{M} \mathrm{HCl}$ in $\mathrm{mm} / \mathrm{y}$

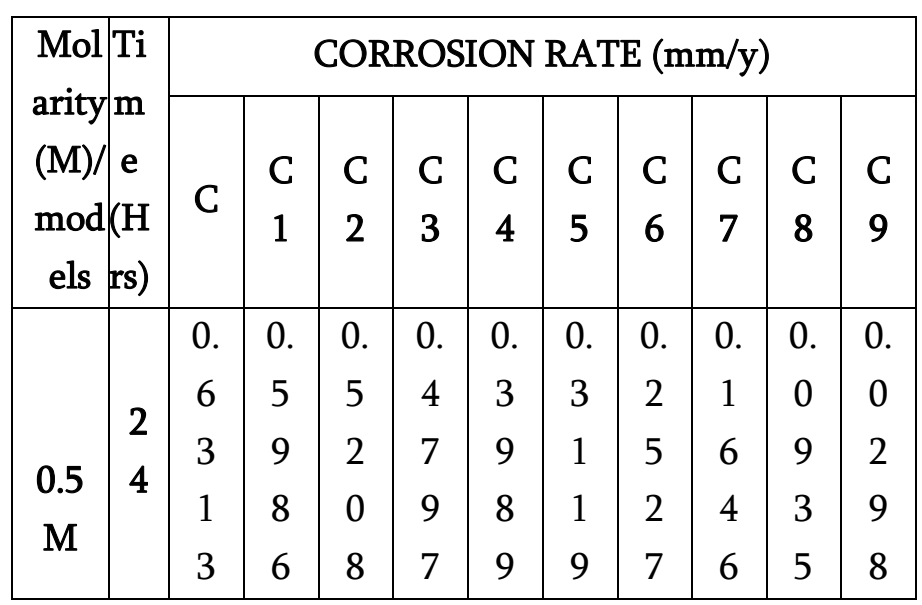

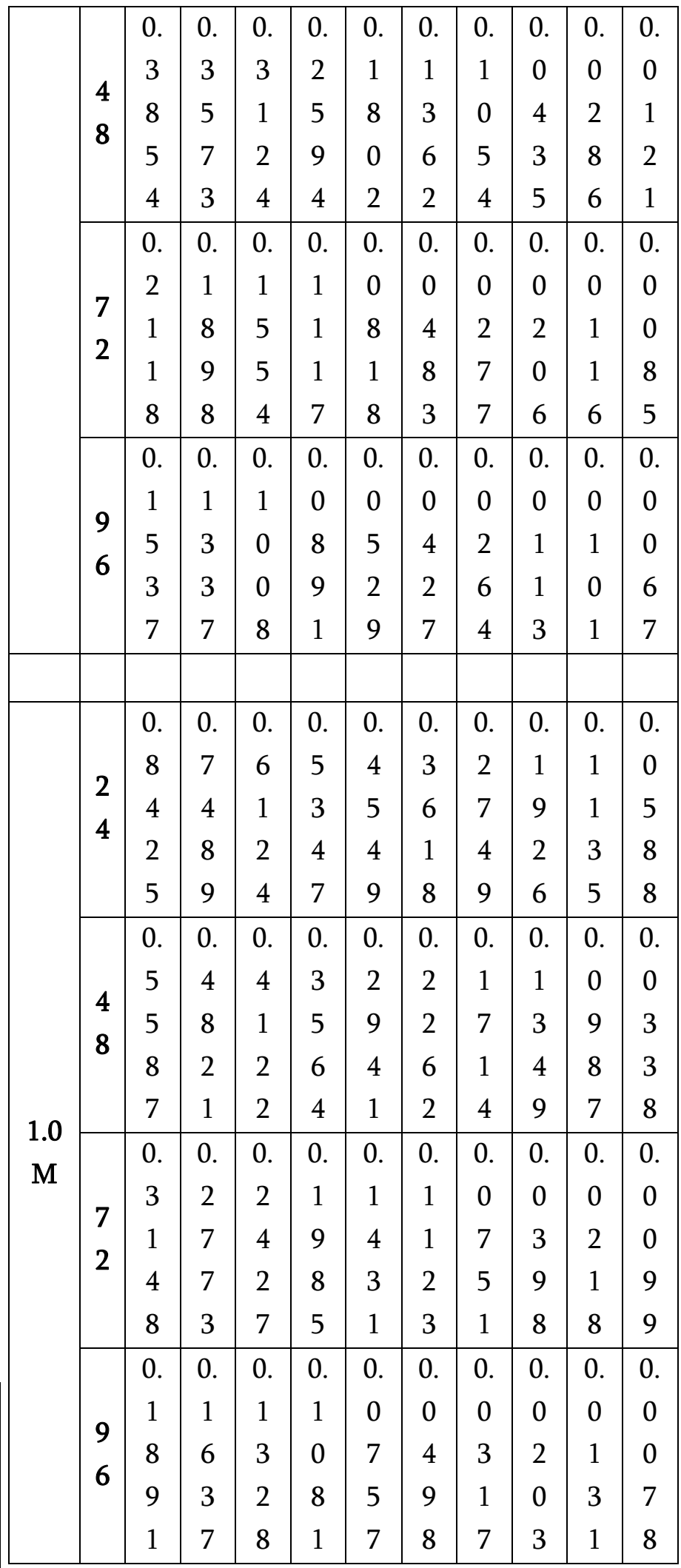




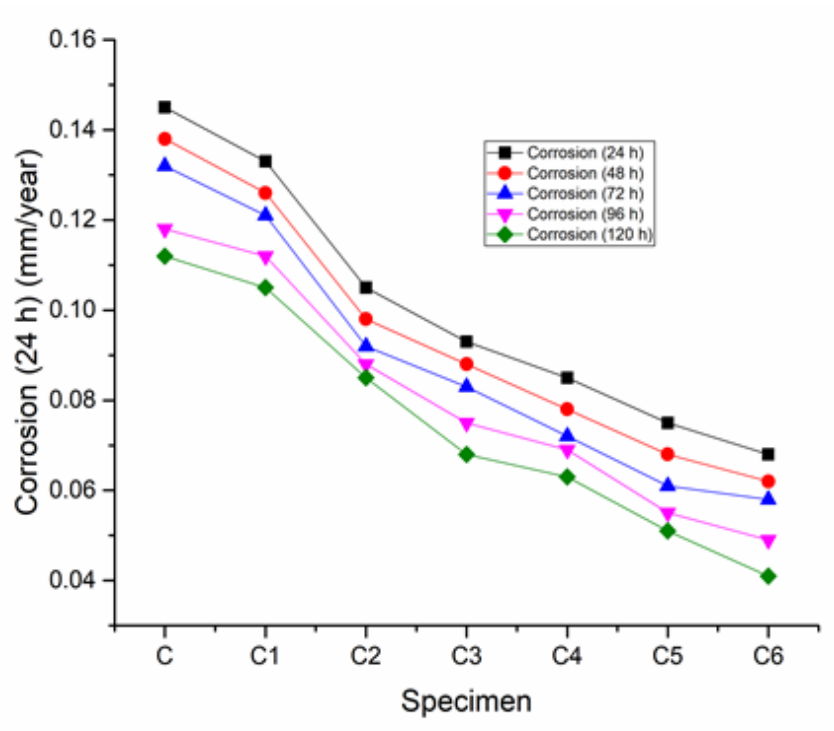

Figure:1.28 Weight loss corrosion for different specimens $(1 \mathrm{M} \mathrm{NaOH})$

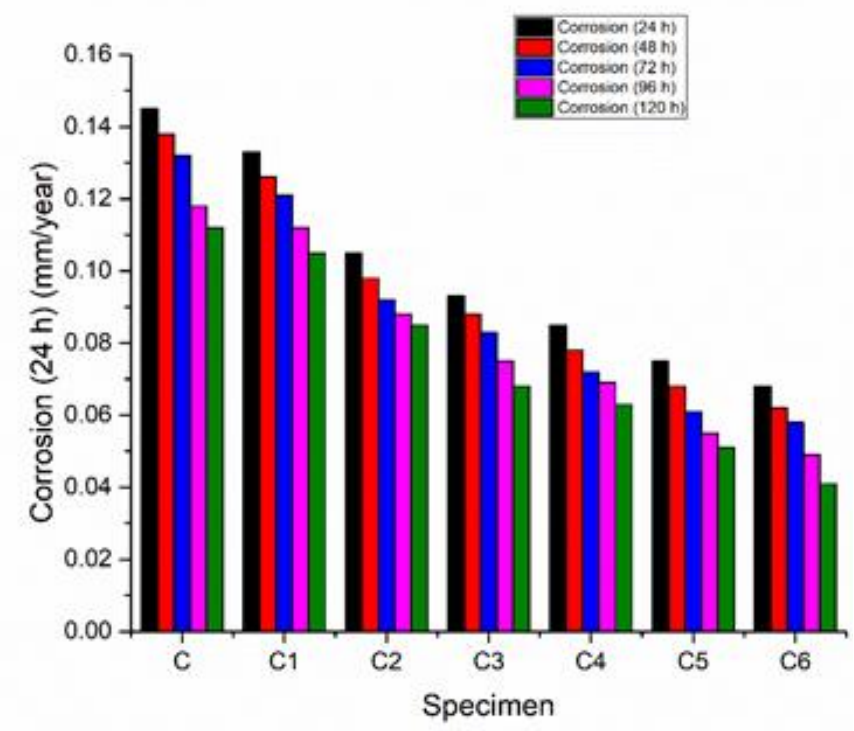

Figure:1.29 Comparison of Weight loss corrosion for different specimens $(1 \mathrm{M} \mathrm{NaOH})$.
In the case of lower \% reinforced hybrid composites, the severity of the acid and the alkaline salt used induces crack formation on the surface, which eventually leads to the formation of pits, thereby causing the loss of material. The presence of cracks and pits on the base alloy surface was observed clearly, since there is no reinforcement provided in any form the lower\% reinforced hybrid composites fails to provide any sort of resistance to the alkaline and acidic medium. Hence the weight loss in case of lower $\%$ reinforced hybrid composites is higher.

The corrosion results indicate that an improvement in corrosion resistance as the \% of CNT and Boron Carbide is increased in the hybrid composite. This shows that CNT and Boron Carbide directly or indirectly influence the corrosion property of the composites. Thus reinforcements act as a relatively inert physical barrier to the initiation and development of corrosion pits and also modifies the microstructure of the matrix material and hence reduces the rate of corrosion.

One more reason for decrease in the corrosion rate inter-metallic region, which is the site of corrosion forming crevice around each particle. Pitting in the composites is associated with the particle -matrix interface, because of the higher concentration in the region. With increase in time pitting would continue to occur at random sites on the particle-matrix interface. The active nature of the crevices would catholically protect the remainder of the matrix and restrict pit formation and propagation.

The corrosion rate was measurement as a function of $\%$ of the both reinforcements in the static immersion test as shown in tabular column. Corrosion rate decreases monotonically with increase in the reinforcement content. In the present case, the corrosion rate of the composites as well as the matrix alloy is predominantly due to the formation of pits, cracks on the surface.
The corrosion rate was measurement as a function of exposure time in the static immersion test as shown. The observed trends in all the cases exhibit a decrease in corrosion rate with increase in test duration. It is clear from the tables and graphs that the corrosion resistance of the composites increases with exposure time. 
It is observed that, the corrosion rate is maximum for $1 \mathrm{~N}$ and $1 \mathrm{M}$ which corresponds to $\mathrm{NaCl}$ and $\mathrm{HCl}$ environment. As normality and molarity value increases corresponding to $\mathrm{NaCl}$ medium and $\mathrm{HCl}$ medium, the corrosion rate decreases. The corrosion rate in the $0.5 \mathrm{~N}$ and $0.5 \mathrm{M}$ of corrosion media are also observed to be less than that of $1 \mathrm{~N}$ and $1 \mathrm{M}$. The corrosion rate of each specimen increases with the concentration of $\mathrm{NaCl}$ and $\mathrm{HCl}$ as expected. In fact, the corrosion attack has a stronger tendency to penetrate more deeply as the concentration of the $\mathrm{NaCl}$ solution $\mathrm{HCl}$ solution from 0.5 to $1.0 \mathrm{~N}$.

\section{VI.CONCLUSION}

The present research work on preparation of Carbon Nano Tube and Boron carbide reinforced Copper metal matrix composite by stir casting and evaluation of mechanical, wear and micro structural characteristics has led to following conclusions.

- Copper/ Carbon Nano Tube / Boron carbide composites have been successfully developed and fabricated with fairly uniform distribution of reinforcements using stir casting technique.

- Corrosion studies of the composite materials is carried out by Weight loss corrosion techniques, It is clearly evident from the critical analysis of the results that with the addition of reinforcements to the composite material, the corrosion rate in weight loss corrosion technique decreases drastically with the duration of time, this is due to the formation of a passive oxide layer on the composite specimen.

- The effect of Carbon Nano Tube and Boron Carbide particles on the sliding wear resistance in Copper alloys varies with the applied load and speed.

- Wear rate increased with the increase in speed and load for every combination of the composite. However with Carbon Nano Tube being the main reinforcement with addition of CNT wear rate has reduced marginally. Addition of Boron Carbide also to some extent decreased the wear rate but Carbon Nano Tube plays a major role in reducing the wear rate.

- Above the critical load, transition to severe wear occurs in unreinforced matrix alloy. But the reinforced MMCs have superior wear resistance.

- With increase in Carbon Nano Tube wear rate has decreased and is clear from the results that as the percentage of Boron Carbide increased in the composite, the wear rate decrease which is a good sign for production of low cost material.

The best wear resistant combination is at $5 \%$ of Boron Carbide and 1\% \& $1.5 \%$ of Carbon Nano Tube as consideration.

\section{REFERENCES}

[1] Wang, X.; Li, Qunqing; Xie, Jing; Jin, Zhong; Wang, Jinyong; Li, Yan; Jiang, Kaili; Fan, Shoushan (2009). "Fabrication of Ultralong and Electrically Uniform Single-Walled Carbon Nanotubes on Clean Substrates". Nano Letters. 9 (9): 3137-3141. Bibcode: 2009NanoL...9.3137W. CiteSeerX 10.1.1.454.2744, doi: 10.1021/n1901260b. PMID 19650638.

[2] Gullapalli, S.; Wong, M.S. (2011). "Nanotechnology: A Guide to Nano-Objects" (PDF). Chemical Engineering Progress. 107 (5): 28-32.

[3] Mintmire, J.W.; Dunlap, B.I.; White, C.T. (1992). "Are Fullerene Tubules Metallic?" Phys. Rev. Lett. 68 (5): 631-634. Bibcode: 1992PhRvL. $68.631 \mathrm{M}$. doi:10.1103/PhysRevLett.68.631. PMID 10045950.

[4] Dekker, C. (1999). "Carbon nanotubes as molecular quantum wires". Physics Today. 52 (5): 22-28. Bibcode: 1999 PhT.52e.22D. doi:10.1063/1.882658.

[5] Martel, R.; Derycke, V.; Lavoie, C.; Appenzeller, J.; Chan, K.; Tersoff, J.; Avouris, Ph. (2001). "Ambipolar Electrical Transport in Semiconducting Single-Wall Carbon Nanotubes". Phys. Rev. Lett. 87 (25): 256805. Bibcode: 2001PhRvL.87y6805M. 
doi:10.1103/PhysRevLett.87.256805. PMID 11736597.

[6] Gray, Theodore (2012-04-03). The Elements: A Visual Exploration of Every Known Atom in the Universe. Black Dog \& Leventhal Publishers. ISBN 9781579128951.

[7] Ridgway, Ramond R "Boron Carbide", European Patent CA339873 (A), publication date: 1934-03-06.

[8] Balakrishnarajan, Musiri M.; Pancharatna, Pattath D.; Hoffmann, Roald (2007). "Structure and bonding in boron carbide: The invincibility of imperfections". New J. Chem. 31 (4): 473. doi:10.1039/b618493f.

[9] Zhang FX, Xu FF, Mori T, Liu QL, Sato A, Tanaka T (2001). "Crystal structure of new rare-earth boronrich solids: REB28.5C4". J. Alloys Compd. 329: 168172. doi:10.1016/S0925-8388(01)01581-X.

[10] Greenwood, Norman N.; Earnshaw, Alan (1997). Chemistry of the Elements (2nd ed.). ButterworthHeinemann. p. 149. ISBN 0-08-037941-9.

[11] Domnich, Vladislav; Reynaud, Sara; Haber, Richard A.; Chhowalla, Manish (2011). "Boron Carbide: Structure, Properties, and Stability under Stress" (PDF). J. Am. Ceram. Soc. 94 (11): 3605-3628. doi:10.1111/j.1551-2916.2011.04865.x. Retrieved 23 July 2015.

[12] Bhaskar Chandra Kandpal, 2Jatinder Kumar, 3Hari Singh, "Production Technologies of Metal Matrix Composite: A Review"IJRMET Vol. 4, Issue 2, Spl 2 May - October 2014.

[13] Ektarawong, A.; Simak, S. I.; Hultman, L.; Birch, J.; Alling, B. (2014). "First-principles study of configurational disorder in B4C using a superatomspecial quasi-random structure method". Phys. Rev. B. 90 (2): 024204. arXiv:1508.07786, Bibcode:2014PhRvB.90b4204E. doi:10.1103/PhysRevB.90.024204.

[14] Ektarawong, A.; Simak, S. I.; Hultman, L.; Birch, J.; Alling, B. (2015). "Configurational order-disorder induced metal-nonmetal transition in B13C2 studied with first-principles superatom-special quasirandom structure method". Phys. Rev. B. 92: 014202. arXiv:1508.07848 Freely accessible.
Bibcode:

2015PhRvB.92a4202E. doi:10.1103/PhysRevB.92.014202.

[15] Sairam, K.; Sonber, J.K.; Murthy, T.S.R.Ch.; Subramanian, C.; Hubli, R.C.; Suri, A.K. (2012). "Development of B4C-HfB2 composites by reaction hot pressing". Int.J. Ref. Met. Hard Mater. 35: 3240. doi:10.1016/j.jirmhm.2012.03.004.

[16] Solozhenko, V. L.; Kurakevych, Oleksandr O.; Le Godec, Yann; Mezouar, Mohamed; Mezouar, Mohamed (2009). "Ultimate Metastable Solubility of Boron in Diamond: Synthesis of Superhard Diamondlike BC5". Phys. Rev. Lett. 102 (1): 015506.

[17] M. S. Nagorka, C. G. Levi, G. E. Lucas and S. D. Ridder: Mater. Sci. Eng. A 104 (1991) 277-289.

[18] M.K. Surappa, P. K. Rohatgi, Preparation and properties of cast aluminium-ceramic particle composites, Journal of materials science, 16(1981), p 983-993.

[19] R. Zitoune, M. El Mansori, K. Vijayan, Tribofunctional design of double cone drill implications in tool wear during drilling of copper mesh/CFRP/woven ply, Wear, 302 (1-2) (2013), pp. 1560-1567.

[20] S.F. Moustafa, A. Torres-Islas, S. Serna, M. AcostaFlores, R.A. Rodriguez-Diaz, J. Colin, Corrosion, electrical and mechanical performance of copper matrix composites produced by mechanical alloying and consolidation, Int. J. Electrochem. Sci., 10 (2015), pp. 1728-1741.

[21] Poulami Majietal, N. Ekere, C. Best, R. Bhatti, Investigation of thermal management materials for automotive electronic control units, Appl. Therm. Eng., 31 (2011), pp. 355-362.

[22] Anish Upadhyaya, A. Kumar, P.R. Sengupta, P.K. Dutta, R.B. Mathur, Improving the mechanical and thermal properties of semi-coke based carbon/copper composites reinforced using carbon nanotubes, J. Adv. Mater. Lett., 5 (5) (2014), pp. 265-271.

[23] Kovalchenko, P. Ozga, W. Maziarz, J. Pstrus, B. Kania, P. Bobrowski, et al., Microstructure and properties of bulk copper matrix composites strengthened with various kinds of CNT 
nanoplatelets, Mater. Sci. Eng., A, 628 (2015), pp. 124-134.

[24] Kime, T. Yener, I. Altinsoy, M. Ipek, S. Zeytin, C. Bindal, The effect of sintering temperature on some properties of $\mathrm{Cu}-\mathrm{SiC}$ composite, J. Alloys Compd., 509 (2011), pp. 6036-6042.

[25] F.Wan, M. Abdel hameed and A. Fathy, "Preparation and Characteristics of $\mathrm{Cu}-$ Al2O3nanocomposite", Journal on Mechanical Design and Production, Vol. 1 Issue 25-33, 20 November-2011.

[26] Bhaskar Chandra Kandpal, Jatinder Kumar, Hari Singh, "Production Technologies of Metal Matrix Composite: A Review ", IJRMET Vol. 4, Issue 2, Spl - 2 May - October 2014

[27] Prabhakar Rao, Jayashree PK, Gowri Shankar MC, Kini A, Sharma SS, Shetty R. "Review on Effect of copper on Stir Cast Aluminium Metal Matrix Composites". Inter-national Journal of Current engineering and Technology.

[28] F Shehata, Al-Hajri M., Petraroli M., Hotton B., Lam P.C., "Influence of silicon carbide particulate reinforcement on quasi static and cyclic fatigue fracture behavior of 6061 Aluminium alloy composites" Materials Science and Engineering A325 (2002) 202-214.

[29] Kenneth Kanayo Alaneme, Development of high strength magnesium based composites using elemental nickel particulates as reinforcement, Journal of Materials Science, 37, pp 24672474, 2002.

[30] Kapoor, R., Vecchio, K.S., "Deformation behavior and failure mechanisms in particulate reinforced $6061 \mathrm{Al}$ metal matrix composites, Materials Science and Engineering A202 (1995) 63-75.

[31] N Sata et al, Materials Science \& Engineering A: Structural Materials; properties, Microstructure and processing, Vol.A197, N 1, Jun 30 1995, pp 11-18.

[32] Alexey Mosh Kovich, W.R. Amitusko, Modelling of $\mathrm{Cu}-\mathrm{Al} 2 \mathrm{O} 3$ metal matrix composite prepared by powder metallurgy route, Int. J. Eng. Adv. Technol. 3, (2013) 330-332.

[33] M. Han, R. Othman, Z. Hussain, Mechanical alloying and sintering of nanostructured tungsten carbide-reinforced copper composite and its characterization, Mater. Des. 32 (2011) 3293-3298.

[34] Q. Zhank, X. He, S. Ren, L. Zhang, M. Wu, C. Guo, W. Cui, X. Qu, Preparation of copper-diamond composites with chromium carbide coatings on diamond particles for heat sink applications, Appl. Therm. Eng. 60 (2013) 423-429.

[35] L. Li, X.H. Qu, X.B. He, B.H. Duan, S.B. Ren, M.L. Qin, Thermo-physical and mechanical properties of high volume fraction $\mathrm{SiCp} / \mathrm{Cu}$ composites prepared by pressureless infiltration, Mater. Sci. Eng., A 489 (2008) 285-293.

[36] Gongjun, L. Liu, Friction and wear properties of copper based composites reinforced with micro and nano-sized $\mathrm{Al} 2 \mathrm{O} 3$ particles, 8th Int. conf. Tribol., 30th Oct-1st Nov. 2014, Sinaia, Romania, 2014, pp. 357-358.

[37] Jena, Yaximo, Modeling of burr size in drilling of aluminum silicon carbide composites using response surface methodology, Eng. Sci. Technol. 19 (2016) 1199-1205.

[38] Entezarian L, M Xiu Development of empirical relationships for prediction of mechanical and wear properties of AA6082 aluminum matrix composites produced using friction stir processing, Eng. Sci. Technol. 19 (2016) 1132-1144.

[39] Yohsimo, Z. Abdel-Hamid, A.M. Abd-Elahi, Copper matrix $\mathrm{SiC}$ and $\mathrm{Al} 2 \mathrm{O} 3$ particulate composites by powder metallurgy technique, Mater. Lett. 53 (2002) 244-249.

[40] J. Fathy, S. Emmer, J. Bielek, Thermal conductivity of $\mathrm{Cu}$-graphite composites, Int. J. Therm. Sci. 90 (2015) 298-302.

[41] F. Tang, J. Ying, Y. Wang, S. Du, Z. Liu, Q. Huang, Effects of CNT content on the microstructure and properties of copper matrix composites, Carbon 96 (2016) 836-842.

[42] W. Tjong, L. Zhou, K. Peng, J. Zhu, L. Wan, Effect of tungsten addition on thermal conductivity of graphite/copper composites, Compos. Part B Eng. 55 (2013) 1-4.

[43] [H. Yin, M. Chug, H. Zhang, A. Tang, B. Ren, X. $\mathrm{He}$, Microstructure and thermal properties of copper matrix composites reinforced by chromium- 
coated discontinuous graphite fibers, Appl. Therm. Eng. 73 (2014) 739-744.

[44] D.D. Zhou, Y.F. Kwon, Z.J. Lu, Microstructural characteristics and formation mechanism of direct laser-sintered $\mathrm{Cu}$-based alloys reinforced with $\mathrm{Ni}$ particles, Mater. Des. 30 (2009) 2099-2107.

[45] W. Manchang, M. Heilmaier, L. Schultz, Highstrength pearlitic steel-copper composite wires for conductors in pulsed high-field magnets, Mater. Sci. Eng., A 303 (1-2) (2001) 127-133.

[46] W. Grünberger, M. Heilmaier, L. Schultz, Highstrength, high-nitrogen stainless steel-copper composite wires for conductors in pulsed high-field magnets, Mater. Lett. 52 (3) (2002) 154-A.S.

[47] Hamada, A. Khosravifard, A.P. Kisko, E.A. Ahmed, D.A. Porter, High temperature deformation behavior of a stainless steel fiber-reinforced copper matrix composite, Mater. Sci. Eng., A (2016), http://dx.doi.org/10.1016/j.msea.2016.03.084.

[48] C. Saldana, S. Swaminathan, T.L. Brown, W. Moscoso, J.B. Mann, W.D. Compton, S. Chandrasekar, Unusual applications of machining: controlled nanostructuring of materials and surfaces, ASME J. Manuf. Sci. Eng. 132-3 (2010) 030908.

[49] T.L. Brown, S. Swaminathan, S. Chandrasekar, W.D. Compton, A.H. King, K.P. Trumble, Low-cost manufacturing process for nanostructured metals and alloys, J. Mater. Res. 17 (10) (2002) 2484-2488.

[50] P. Iglesias, A.E. Jiménez, M.D. Bermúdez, B.C. Rao, S. Chandrasekar, Steel machining chips as reinforcements to improve sliding wear resistance of metal alloys: study of a model Zn-based alloy system, Tribol. Int. 65 (2013) 215-227.

[51] K.K. Alaneme, A.O. Aluko, Production and agehardening behaviour of Borax pre-mixed $\mathrm{SiC}$ reinforced $\mathrm{Al}-\mathrm{Mg}-\mathrm{Si}$ alloy composites developed by double stir casting technique, West Indian J. Eng. $34(1 / 2)(2012) 80-85$.

[52] K.K. Alaneme, T.M. Adewale, Influence of rice husk ash-silicon carbide weight ratios on the mechanical behaviour of $\mathrm{Al}-\mathrm{Mg}-\mathrm{Si}$ alloy matrix hybrid composites, Tribol. Ind. 35 (2) (2013) 163 172.
[53] T.K. Vyas, A. Pandey, A review on investigation of copper matrix composite by using stir casting method, Indian J. Appl. Res. 5 (1) (2015) 75-77.

[54] K.K. Alaneme, Influence of thermo-mechanical treatment on the tensile behaviour and CNT evaluated fracture toughness of borax premixed silicon carbide reinforced aluminium (6063) matrix composites, Int. J. Mater. Mech. Eng. 7 (1) (2012) 96-100.

[55] K.K. Alaneme, K.O. Sanusi, Mechanical and wear behaviour of rice husk ash-alumina-graphite hybrid reinforced aluminium based composites, Eng. Sci. Technol. Int. J. 18 (3) (2015) 416-422.

\section{Cite this article as :}

Dr. Tukaram Jadhav, Dr. H. K. Shivanand, Dr. Ranjith V, Verma R, Puneeth P, "Effect of Tribological Properties on Boron Carbide and CNT Reinforced Copper based Composites", International Journal of Scientific Research in Science and Technology (IJSRST), Online ISSN : 2395-602X, Print ISSN : 23956011, Volume 8 Issue 3, pp. 148-165, May-June 2021. Available at

doi: https://doi.org/10.32628/IJSRST218325

Journal URL : https://ijsrst.com/IJSRST218325 